\title{
A formação do bibliotecário para atuar em bibliotecas digitais: uma questão a aprofundar
}

Helania Oliveira Madureira

\begin{abstract}
Mestre em Educação - Universidade Estácio de Sá (RJ). Bibliotecária da Universidade Federal Fluminense -
\end{abstract}

Lúcia Regina Goulart Vilarinho

\section{Doutora em Educação pela UFRJ.Docente do Programa de Pós-graduação em Educação da Universidade Estácio de Sá}

A pesquisa focalizou a formação de bibliotecários para o trabalho em bibliotecas digitais (BD), buscando responder às seguintes indagações: (a) como os cursos de formação de bibliotecários preparam esse profissional para atuar em BD; (b) que dificuldades estes sujeitos encontram em seu trabalho; e (c) como mantém sua formação atualizada. A natureza dessas indagações, baseada na fala de bibliotecários, direcionou a pesquisa para a dimensão qualitativa. As informações foram coletadas junto a bibliotecários experientes e recém formados, com apoio de questionário online, sendo as respostas analisadas com orientações da técnica de Análise de Conteúdo. Os resultados foram confrontados ao embasamento teórico que abordou três tópicos: o moderno profissional de informação; formação do bibliotecário para atuar em BD; e educação continuada do bibliotecário. Dentre as conclusões obtidas destacam-se: (a) a formação do bibliotecário está longe de privilegiar o perfil do moderno profissional da informação; e (b) os sujeitos encontram-se preocupados com processos de organização de suas bases de dados, que passam a ser online. Há indícios de que ainda se prendem à função básica da biblioteca tradicional, que é manter a memória coletiva da sociedade, desconsiderando que na era da 
internet a memória se torna volátil, transformando-se constantemente.

Palavras-chave: Bibliotecas Digitais; Formação do bibliotecário; Moderno profissional de informação.

\section{The Librarian training to work in virtual libraries: an issue to deepen}

The research focused on the training of librarians to the work in digital libraries ( $D L)$, viewing to answer the following investigations: (a) how do these librarians training courses prepare this professional to work in $D L$ ? (b) Which difficulties do these subjects find in their everyday work? (c) How do they keep updated? The nature of these investigations, based on these librarians' statements directed this research towards a qualitative dimension. The data were collected from experienced librarians and recently graduated ones, supported by online questionnaires, whose responses were analyzed taking into consideration, as a theoretical support, The Contend Analysis Technique. The results found were confronted with the theoretical references adopted, that approached three topics: the modern information professional; the librarian training to work in $D L$; and the librarian's continued education. Among the results acknowledged it can be highlighted: (a) the librarian's training is far from the profile demanded by the modern information professional; (b) the subjects are concerned with the organization processes related to their database, which are currently online. There are indications that those librarians are still attached to the traditional paradigm, whose main objective is to keep the society's collective memory disregarding the fact that in the Internet era that memory turns out to be volatile and in constant transformation.

Keywords: Digital libraries; Librarian training; Modern information professional.

Recebido em 16.04.2010 Aceito em 18.10.2010 


\section{Considerações iniciais}

Ao longo do século $X X$, as bibliotecas passaram a sentir mais intensamente o impacto das tecnologias da informação e comunicação (TIC), na medida em que muitas delas organizaram acervos cinematográficos e videográficos (vídeos), frutos de uma produção mais rápida, visualizados com o simples apoio de aparelhos de TV. A possibilidade de juntar recrsos dessa natureza foi permitindo a estruturação de espaços que assumiram os mesmos princípios básicos da biblioteca; surgem, então, as cinematecas ${ }^{1}$ e videotecas ${ }^{2}$.

Esse impacto tornou-se mais contundente no final do século $X X$, podendo ser relacionado à nova revolução técnico-industrial, que se projetou sobre as capacidades intelectuais e a liberação do trabalho humano (SCHAFF, 1992). Segundo esse autor, a segunda revolução técnico-industrial compreende três aspectos inter-relacionados: (a) revolução microeletrônica; (b) revolução microbiológica; e (c) revolução energética, caracterizada principalmente pelo domínio da fusão nuclear. No bojo desse processo revolucionário, que faz surgir a "sociedade informática", situa-se a ciência que assume paulatinamente "o papel de força produtiva" (idem, p. 43).

Segundo Dyson (1994, apud LEVACOV, 1997, p. 1):

da mesma forma que a Revolução Industrial não eliminou a agricultura, mas a marginalizou de forma crescente como fonte de renda, trabalho e poder, a Revolução da Informação faz migrar o capital para a própria informação, sua distribuição e recuperação. A sociedade e a economia tornam-se, cada vez mais, information-based. O declínio acentuado dos custos de hardware e software e o crescimento extraordinário do acesso comercial auxiliam e aceleram esta transição. Ao subverter a economia de produção em massa, as novas tecnologias da informação diminuem os custos da diversidade, tanto em produtos quanto pessoal, desmassificando nossas instituições e nossa cultura, bem como criando um novo potencial para a liberdade humana, uma vez que eliminam a necessidade do paradigma institucional central da vida moderna: a burocratização.

\footnotetext{
${ }^{1}$ Um bom exemplo de cinemateca está no Museu de Arte Moderna do Rio de Janeiro, funcionando há mais de 50 anos. A história desta instituição e sua programação podem ser vistas em <www.manrio.org.br $>$. Acesso em: 18 ago. 2009.

${ }^{2}$ Reconhecida pelas suas pesquisas na área da saúde, a Fundação Oswaldo Cruz, localizada no município do Rio de Janeiro, possui uma videoteca que tem por finalidade não apenas produzir vídeos, como, também, reproduzilos e oferecer à comunidade científica. $\mathrm{O}$ trabalho educacional desta instituição nesta área pode ser visualizado em: <http://www.fiocruz.br/cgi/cgilua.exe/sys/start.htm?sid=65 >. Acesso em: 18 ago. 2009.
} 
A expansão da Sociedade Informática tem revolucionado as relações sociais, de tal modo que a clássica divisão da sociedade em classes, que distingue os possuidores dos não possuidores dos meios de produção, incorpora outra questão: os que possuem acesso à informação e os que estão excluídos. Essa problemática é um dos grandes entraves à construção das sociedades democráticas. A privação do conhecimento e o pensamento humano apoiado em modelos que simplificam, reduzem e distorcem a realidade (MORIN, 2001) são elementos propiciadores da cegueira política e intelectual.

Uma sociedade permeada por processos informatizados, pela inteligência artificial e coletiva (LÉVY, 2004) coloca novas exigências às bibliotecas e àqueles que se dedicam a conservar e divulgar seu acervo. As mudanças em curso interessam às bibliotecas, enquanto centros de informação e pesquisa, e seus bibliotecários, situados como organizadores, coletores e socializadores de informações específicas.

Tarapanoff; Araújo Júnior e Cormier (2000, p. 93) afirmam que é chegada a hora do bibliotecário agregar valor a produtos e serviços, o que "significa imprimir aos mesmos uma diferenciação que os torna mais atraentes aos olhos dos consumidores, seja em termos de qualidade, rapidez, durabilidade, assistência ou preço". Para que este personagem potencialize o valor de seus produtos e serviços, precisa tornar-se consumidor da própria informação, aceitar a inovação (querer mudar, não ter medo de correr risco, avaliar a mudança com pesquisa) e promover a sua educação continuada. Nesta direção, desde o final da década de 1980 e início dos anos 1990, com a nova ordem social voltada para a globalização de mercados e a quebra de paradigmas, foi sendo construído um novo conceito para esse profissional, situando-o como: "profissional da informação". Como se define este Moderno Profissional da Informação (MPI)?

Se antes a atividade do bibliotecário podia ficar restrita aos limites físicos de uma biblioteca e de uma coleção, agora o uso difundido da tecnologia a serviço da informação transpõe barreiras físicas e institucionais. Até poucos anos atrás, o usuário do acervo era percebido em uma perspectiva passiva; hoje, as atenções se voltam para o cliente interativo. Por outro lado, a escassez de recursos, que obriga a integração e o compartilhamento de bases de dados, a competição industrial e o avanço tecnológico acenam para a informação estratégica.

Sintetizando essa tendência, Mueller (1985) e Guimarães (1994) caracterizaram o Profissional da Informação como aquele que é capaz de fornecer a informação certa, da fonte certa, ao cliente certo, no momento certo, da forma certa e a um custo que justifique seu uso. Já Arruda, Marteleto e Souza (2000), após pesquisa em literatura específica, verificaram que o redimensionamento do Profissional da Informação se 
inicia por um processo de adaptação do acervo cognitivo e da personalidade às novas condições do trabalho no mundo globalizado, marcado pela expressiva presença das tecnologias de informação e comunicação. Para esses autores, o perfil do bibliotecário, desenhado nos documentos estudados, aproxima-se do perfil requerido pela especialização flexível, ou seja, deve atender às demandas do setor produtivo que busca um trabalhador apto a interagir em consonância com as metas e os objetivos da organização a qual se vincula. Entendem que não há um modelo rígido de Profissional da Informação e salientam que as exigências de redimensionamento têm a ver com o novo modelo econômico (capitalismo globalizado), que introduz novas formas de gestão do trabalho e de socialização dos indivíduos.

Ponjuan (1993, p. 22) fala das qualidades que garantem o $\mathrm{M}$ ao MIP (Modern Information Professional):

[...] eu, particularmente, penso que há profissionais da informação com e sem o M. Um moderno profissional da informação perde o $M$ quando ele - ou ela - perde a capacidade de se adaptar a um meio em mudança. Flexibilidade, inovação, imaginação e criatividade são alguns dos ingredientes vitais.

O MIP é hoje uma realidade do novo contexto sócio-econômico mundial. Se antes o profissional, empunhando um diploma universitário e pautando-se em conhecimentos que havia recebido em sua formação, ocupava seu lugar na sociedade a partir das prerrogativas legais que lhe eram dadas, hoje isso só não basta. Cada vez mais se tornam indispensáveis os profissionais de mente aberta, atentos e flexíveis, capazes de enfrentar os desafios impostos pelas mudanças. A multiplicidade de suportes e sua variedade de usos passaram a exigir um profissional com mais conhecimentos e, por conseguinte, habilidades, que põem em questão os rigorosos limites profissionais restritos à graduação. É, pois, chegada a hora das instituições, ligadas à formação de profissionais na área de informação, preocuparem-se com o verdadeiro MIP, considerando as especificidades de cada suporte e as realidades nas quais esses profissionais irão atuar.

Diante desse contexto, nos indagamos: o ensino de Biblioteconomia, no Brasil, forma MIP? Os egressos do curso de biblioteconomia estão aptos a atuarem em bibliotecas digitais (BD)?

Para não correremos o risco de realizar uma pesquisa cuja problemática já tivesse sido investigada, levantamos no Banco de Teses e 
Dissertações da $\mathrm{CAPES}^{3}$, tanto na área da educação como na de biblioteconomia, os trabalhos que foram desenvolvidos nos últimos sete anos (a partir de 2000) ${ }^{4}$, selecionando aqueles que tratavam da relação biblioteca digital - educação. O levantamento, conduzido por palavraschave, encontrou 350 pesquisas distribuídas pelos seguintes temas: (a) biblioteca e educação - 270 teses/dissertações; (b) formação do bibliotecário - 60 trabalhos; (c) biblioteca digital (ou virtual) e educação 16 estudos; e (d) biblioteca digital e formação do bibliotecário - 4 pesquisas. Verificamos, então, a existência de sete estudos que se aproximavam de nossa proposta. O que mais nos chamou a atenção foi o fato de que todos se preocupavam com a educação continuada dos profissionais da informação para atuarem em contextos marcados pela presença das TIC. Com ele, verificamos, também, que a atuação em biblioteca digital não foi considerada, apesar de estarmos há alguns anos na era da virtualidade produzida pela expansão da Internet. Tal fato nos estimulou, então, a realizar uma pesquisa cujo foco de investigação em nosso país, no meio acadêmico, é pouco estudado.

Considerando a lacuna encontrada, pensamos ser oportuno aprofundar a formação do bibliotecário para atuar em bibliotecas digitais, discutindo a prática desenvolvida nesse espaço, o que implicava conhecer as dificuldades do 'novo' profissional e como ele investe em seu aperfeiçoamento. Para dar conta desta proposta de investigação, elaboramos as seguintes questões de estudo: (a) como os cursos de formação de bibliotecários vêm preparando esse profissional para trabalhar em bibliotecas digitais? (b) que dificuldades esse profissional encontra em seu trabalho? (c) que caminhos percorre para manter sua formação atualizada?

\section{Procedimentos metodológicos da pesquisa}

Considerando o teor das questões de estudo - relacionado à formação (inicial e continuada) do bibliotecário e às dificuldades encontradas no trabalho que ele concretiza em BD - a pesquisa assumiu uma abordagem predominantemente qualitativa.

A investigação qualitativa tem por objetivo básico colaborar para o desenvolvimento da teoria (STRAUSS; CORBIN, 2008), ou seja, busca informações e as analisa / compara / sintetiza, de modo a oferecer subsídios que ampliem um determinado campo teórico.

Com base nessa diretriz, estabelecemos as etapas da coleta de dados: (a) levantamento via sites das instituições de ensino superior

\footnotetext{
${ }^{3}$ CAPES - Coordenação de Aperfeiçoamento de Pessoal de Nível Superior < $\underline{w w w . c a p e s . ~ g o v . b r />. ~ A c e s s o ~ e m: ~}$ 27 de julho de 2009.

4. Optamos por uma busca nos últimos sete anos tendo em vista que é a partir da virada do milênio que a presença do computador e da internet se intensifica nos ambientes educacionais.
} 
(IES), situadas na região sudeste ${ }^{5}$, que oferecem curso de biblioteconomia e suas respectivas grades curriculares, para verificar semelhanças e diferenças entre elas, com atenção especial à presença de disciplinas que se referem ao processamento digital de informações, o que pode ser indicativo de inovação em uma proposta de graduação desse profissional; (b) mapeamento das IES incluídas, neste levantamento, que possuíam bibliotecas digitais e identificação da sua origem como BD; (c) levantamento dos serviços oferecidos por essas bibliotecas. Nesse momento, era importante saber se havia (ou não) um modelo de biblioteca digital; (d) mapeamento dos endereços eletrônicos dos profissionais responsáveis pelas bibliotecas digitais selecionadas, para que pudessem ser contatados e respondessem às perguntas capazes de oferecer um conjunto de informações que articulassem as respostas às questões do estudo; e (e) elaboração do instrumento de coleta de dados um questionário online com perguntas fechadas (sobre formação e experiência como bibliotecário) e abertas (desmembradas das questões de estudo, objetivando atender à parte substantiva da pesquisa) - que, após sua validação por dois profissionais dessa área, ambos com Mestrado em Educação, foi remetido aos bibliotecários, situados, a partir daí, como sujeitos da pesquisa.

A análise dos dados coletados nas perguntas abertas do questionário foi conduzida com apoio da técnica de Análise de Conteúdo (BARDIN, 2000), com o objetivo de se identificar os núcleos temáticos que apareciam como recorrentes nas falas dos bibliotecários e, também, aqueles que se encontravam isolados, mas que ali estavam, por algum motivo especial, merecendo ser aprofundados.

Os resultados depurados da interpretação das respostas oferecidas pelos bibliotecários no questionário online foram relacionados às considerações teóricas escolhidas para subsidiar a pesquisa, as quais incidiram sobre três aspectos: conceitos de biblioteca digital e de moderno profissional de informação (MIP); a formação do bibliotecário para atuar em BD; e a educação continuada do bibliotecário.

\section{Do bibliotecário ao moderno profissional da informação}

A formação do bibliotecário, de um modo geral, se dá em dois níveis: graduação e pós-graduação. No primeiro, os objetivos fundamentais, segundo o que encontramos em sites de universidades 6 reconhecidas no país, são: (a) formar profissionais capazes de acompanhar as transformações da sociedade, compreendendo o papel da biblioteca neste processo, identificando demandas de informação e

\footnotetext{
${ }^{5}$ A decisão de pesquisar na região sudeste prende-se ao fato dela ser, entre as demais regiões do país, a que mais congrega IES com Bibliotecas Digitais (BD).

${ }^{6}$ UFRJ, UFF, UFMG, USP, PUC-Campinas, UFSC.
} 
propondo soluções inovadoras; (b) preparar profissionais para atuarem como especialistas no tratamento e difusão de informações, apoiados nas tecnologias da informação; e (c) capacitar profissionais para atuarem em nível de planejamento, administração, assessoria e prestação de serviços em redes e sistemas, bibliotecas, centros de documentação e serviços de informação.

Analisando-se a profissão de Biblioteconomia no Brasil, no transcorrer do último século, observamos que ela passou por distintos e marcantes períodos históricos, como apontam Mueller (1985); Guimarães (1994); Guimarães e Guarezzi (1994).

De início, encontramos a visão do bibliotecário erudito, de formação eminentemente humanista, ligado à cultura e às artes, recebendo forte influência francesa da École de Chartres. Tal influência norteou a criação do primeiro curso de Biblioteconomia do país: o da Biblioteca Nacional (1911-1930). Em seguida, emerge a perspectiva de bibliotecário com formação técnica, sob nítida influência norte-americana, voltada para o tratamento e a organização de documentos (1930-1960). Esta influência se expressa nos primeiros cursos de Biblioteconomia, localizados em São Paulo. Na década de 1960, ocorre o reconhecimento oficial da profissão em nível superior, com o estabelecimento de uma legislação profissional e a criação de órgãos de classe. A partir daí, surgem os primeiros cursos de pós-graduação, inicia-se o desenvolvimento da pesquisa e são publicados os primeiros periódicos científicos na área (década de 1970).

Nos anos oitenta, surgem as reformas curriculares dos cursos de graduação em Biblioteconomia, incorporando uma visão de bibliotecário como agente cultural de informação. $E$, a partir dos anos noventa, a formação passa a ser visualizada na perspectiva de MIP, consolidada com a expansão de tecnologias que vão permitir a criação de bibliotecas digitais, também conhecidas como 'bibliotecas sem parede', capazes de disponibilizar informações sem a necessidade de uma instalação física onde estejam armazenados livros, periódicos e/ou qualquer outro tipo de suporte de informação.

Cunha (2008) esclarece que a biblioteca digital combina a estrutura e a coleta da informação habitualmente usadas por bibliotecas e arquivos tradicionais com o uso da representação digital. Segundo esse autor, a informação digital pode ser rapidamente acessada em todo o mundo, copiada para preservação, armazenada e rapidamente recuperada. A grande vantagem da BD é sua capacidade de entregar a informação desejada diretamente na mesa do usuário, evitando os desgastes decorrentes do uso intenso dos documentos impressos.

Para Marcondes (2006, p.16), o conceito de BD ainda está emergindo. Não é possível uma definição completa e acabada face à continua evolução das tecnologias de informação e comunicação. Em uma tentativa de definição, esse autor diz que a BD tem como base 
informacional conteúdos em formato digitais que incluem livros, periódicos, teses, imagens, vídeos e outros que estão "armazenados e disponíveis para acesso segundo processos padronizados, em servidores próprios ou distribuídos e acessados via rede de computadores em outras bibliotecas ou redes de bibliotecas da mesma natureza".

Entre as vantagens das bibliotecas digitais podemos citar: (a) consulta gratuita às publicações; (b) acesso a uma multiplicidade de recursos informacionais disponíveis na rede; (c) velocidade da comunicação científica propiciada pela publicação direta na rede; (d) crescimento de usuários acessando, diretamente, a informação; (e) preservação de documentos; (f) impressão e distribuição versus distribuição e impressão; (g) personalização dos documentos; (h) leitura de texto com diferentes vozes para portadores de deficiência visual; (i) disseminação seletiva da informação (DSI); (j) localização e inclusão imediata de documentos e objetos digitais na rede, entre eles citam-se: contratos, processos e pareceres, atas e pautas, manuais, apostilas, fotos, slides e negativos, plantas e mapas, recortes, clippings e periódicos, normas e procedimentos; (k) localização instantânea de informação em milhões de páginas, contabilizando ganhos de tempo e produtividade; e (I) preservação de documentos históricos, raros e frágeis, tais como livros, jornais, fotos, negativos, garantindo que não sofram desgaste nem sejam desencadernados (REZENDE, 2000).

Rodrigues (1995) aponta alguns problemas que limitam o acesso às bibliotecas digitais: (a) infra-estrutura; (b) necessidade de aperfeiçoar ou desenvolver novos métodos de identificação, catalogação, organização, classificação e indexação dos recursos eletrônicos; (c) defesa do direito autoral e copyright, para não prejudicar os que participam do processo de produção e distribuição, entre eles: autores, editores, bibliotecas; e (d) necessidade de mudanças organizacionais e superação de barreiras burocráticas na implantação desse tipo de biblioteca.

Levacov (1997) também fala dos obstáculos da BD e os classifica conforme sua origem: (a) legais e éticos; (b) econômicos; (c) ausência de padrões de descrição de páginas - trata-se das questões dos endereços longos e difíceis de memorizar, pois não existe um padrão; e (d) metáforas e interfaces - questão de autenticidade e integralidade de documentos, obsolescência das tecnologias de preservação, armazenamento e recuperação da informação.

De acordo com o Instituto Brasileiro de Informação em Ciência e Tecnologia (IBICT) ${ }^{7}$, já podemos observar em nosso país um crescimento significativo das bibliotecas digitais, com especial destaque para a região sudeste (foco de nossa pesquisa) onde encontramos os seguintes números: (a) São Paulo - 58; (b) Rio de Janeiro - 45; e (c) Minas Gerais -

\footnotetext{
${ }^{7}$ O site do IBICT está disponível em: http://www.ibict.br. Acesso em: 21 maio 2008.
} 
12. A soma dessas BD (115) equivale a $64 \%$ de todas as bibliotecas virtuais do país.

Diante da expansão de BD, cabe indagar: como se define o MIP? Em termos práticos, podemos dizer que a atividade do MIP estaria centrada em algumas linhas básicas de ação, dentre as quais cabe mencionar a gerência de unidades (e sistemas) de informação, o que o leva a envolverse diretamente com o ambiente informativo, o staff informativo e os recursos informativos, dando-Ihes coesão e coerência.

Se antes a visão do bibliotecário, do arquivista ou do museólogo era a de um técnico em seu sentido estrito, hoje se impõe a visão do manager, ou seja, aquele que: (a) racionaliza procedimentos (e gastos), busca (compartilha) recursos e parcerias, integrando sua unidade de informação à sistemas mais amplos; (b) sabe tratar da informação em relação ao MIP/fonte de informação, o que segundo Smith $(1986$, p.11) se define como capacidade de "reunir e organizar para achar"; e (c) pratica uma ação social crítica, isto é, questiona a exacerbação do tecnicismo profissional. Atuar na gestão da informação é, sem dúvida, a principal atividade atribuída ao MIP.

Para Castro (2002), alguns aspectos do perfil do MIP se sobressaem: (a) atenção às técnicas biblioteconômicas e documentais; (b) atitudes gerenciais pró-ativas; (c) desenvolvimento de atividades em espaços onde haja necessidade de informação; (d) tratamento e disseminação de informação, independente do suporte físico; (e) espírito crítico e bom senso; (f) atendimento real e/ou virtual aos clientes; ( $g$ ) profundo conhecedor dos recursos informacionais disponíveis e das técnicas de tratamento da documentação com domínio das tecnologias mais avançadas; (h) domínio de línguas estrangeiras; (i) ativas práticas interdisciplinares; (j) fusão entre as abordagens qualitativas e quantitativas; (I) estudo das necessidades de informação dos clientes e avaliação dos recursos dos sistemas de informação; $(m)$ relação informação e sociedade; (n) domínio dos saberes biblioteconômicos e áreas afins; (o) planejamento e gerenciamento de sistemas de informação; (p) preocupação na análise, comunicação e uso da informação; (q) intenso processo de Educação continuada; (r) treinamento em recursos informacionais; e (s) ativa participação nas políticas sociais, educacionais, científicas e tecnológicas.

Complementando esse rol de capacidades, Pando e Guimarães (2006) consideram que a principal função dos modernos profissionais da informação diz respeito à mediação da informação entre o estoque de informação e os usuários, tidos hoje como sujeitos mais exigentes e conscientes de seus direitos. Para esses autores o grande desafio do MIP está na sua capacidade de gerenciar a grande quantidade de informações que são, a todo momento, ampliadas, modificadas, disponibilizadas. 
Será que as escolas de Biblioteconomia e Ciência da Informação ${ }^{8}$ formam profissionais com essas capacidades, ou seja, sujeitos preparados para agir como diretores de informação, gerentes de informação, agentes de informação, gestores e outras?

No contexto da educação continuada, Tarapanoff (1999, p. 31) define um ponto importante: "é necessário alfabetizar digitalmente todos os profissionais da informação no Brasil, em especial os bibliotecários, para que estes possam atuar como multiplicadores e alfabetizadores na sociedade da informação". Muitas habilidades são conseguidas durante o aprimoramento profissional, dentro de áreas distintas das que os profissionais atuam. Listá-las na Biblioteconomia seria praticamente impossível, pelo fato do bibliotecário ser um profissional apto a gerenciar informação em diversas organizações, podendo também atuar em cargos e funções diferenciadas, que também exigem habilidades e competências diferenciadas.

Mas, a quem cabe a responsabilidade por este tipo de formação? De um modo geral, o profissional da informação é apontando como o principal responsável por sua educação continuada, tendo em vista que ele é quem melhor conhece suas necessidades. Esse conhecimento aciona outro componente importante, que é a motivação, de teor subjetivo, mais facilmente estimulado pelo próprio indivíduo. Motivado, o bibliotecário tende a se manter sintonizado com as possibilidades de aperfeiçoamento e acaba percebendo as opções de que dispõe para sua formação continuada: acesso à literatura especializada, nacional e estrangeira; envolvimento em projetos de pesquisa; participação ativa em grupos profissionais; participação em congressos e outros eventos; uso de redes eletrônicas de informação; e acesso à internet para utilização de bancos de dados, navegação em sites, participação em lista de discussão.

Nocetti (1982) adverte que existem vários argumentos que justificam a limitada procura por formação contínua por parte desses profissionais, que incluem desde a falta de condições financeiras até a pouca oferta de propostas dessa natureza. Entre os argumentos situamse: (a) as atividades de educação continuada implicam, geralmente, em gastos que o nível salarial nem sempre permite enfrentar; (b) a participação em atividades de educação continuada não é comumente reconhecida como parâmetro para promoções funcionais e/ou salariais; (c) os bibliotecários nem sempre contam com o financiamento das instituições empregadoras, em função da falta de recursos nos orçamentos para esse fim; (d) existem bibliotecas com um número mínimo de bibliotecários, o que impede a saída do profissional para um

\footnotetext{
${ }^{8}$ No Brasil, existem atualmente 39 cursos de Biblioteconomia e/ou Ciência da Informação, oferecidos por universidades públicas e particulares, distribuídos da seguinte forma: universidades federais e estaduais - 26; faculdades particulares - 13 .
} 
curso regular de pós-graduação ou de extensão; (e) a literatura biblioteconômica é carente de registros de pesquisa que atendam aos interesses e necessidades dos bibliotecários em relação ao assunto em pauta; (f) poucos artigos e documentos registram experiências de educação continuada de bibliotecários, o que seria importante para aprimorar novos planejamentos; e (g) as escolas de Biblioteconomia, com algumas exceções, têm negligenciado o aperfeiçoamento dos egressos bem como o investimento em maior interação com as associações de bibliotecários, no que tange ao planejamento de educação continuada.

Cabe, pois, estudar formas de ajudar o bibliotecário - o MIP - a encontrar alternativas que o levem a conquistar os conhecimentos capazes de darem consistência ao seu principal papel - um disseminador do conhecimento na Sociedade da Informação.

\section{A precariedade da formação do moderno profissional da informação no âmbito do ensino de graduação: uma conclusão a aprofundar}

Em nossas considerações iniciais, apresentamos três questões de estudo que foram respondidas com os dados coletados em campo e pensadas à luz das considerações teóricas apresentadas na seção anterior.

Tivemos a colaboração de 23 sujeitos, a saber: 17 profissionais com experiência na atividade de bibliotecário e seis recém formados, que responderam a questionários encaminhados via correio eletrônico. Os 17 bibliotecários atuavam em bibliotecas que se apresentavam, em site especializado, como possuidoras de BD, o que, de início, nos animou em relação a uma coleta significativa de dados. Os recém formados não tinham experiência de trabalho em BD, mas deles o que se interessava recolher eram dados sobre o conhecimento oferecido ao longo de seu curso de graduação sobre esse tipo de biblioteca.

Nossa primeira questão de estudo visava saber como os cursos de formação de bibliotecários vêm preparando esse profissional para trabalhar em bibliotecas digitais. Separamos as respostas em dois grupos: as dos bibliotecários experientes e as dos novatos.

Apenas $41 \%$ dos profissionais experientes consideraram satisfatória a formação oferecida e justificaram a posição assumida: de um modo geral, as universidades não oferecem a capacitação necessária para o trabalho com as tecnologias; no entanto, ensinam a lógica necessária aos processos de seleção, organização, atualização, depuração, armazenamento e divulgação dos dados, o que constitui a base das atividades desse profissional. O conhecimento prático vem depois com a experiência profissional e a realização de cursos de atualização. Salientaram que o MIP precisa ir além do saber lidar com as tecnologias digitais; ele tem, necessariamente, que saber interagir com o usuário, ser 
dinâmico, participativo, entre outras qualidades, o que implica vivência prática intensa. Portanto, para esse grupo de sujeitos, a base teórica deve ser sólida de modo a garantir o domínio e a versatilidade dos processos lógicos de tratamento da informação. Um deles salientou que é da interação qualidade do curso - qualidade do aluno que se tem o profissional competente.

Em contrapartida, $29 \%$ desses profissionais afirmaram que a formação não atende às necessidades de um MIP, tendo em vista problemas como: falta de laboratórios de informática destinados especificamente ao curso, estágios supervisionados realizados apenas em bibliotecas tradicionais, falta de professores atualizados em BD e conteúdos incompletos. Consideraram que são poucas as instituições que investem na qualidade do estágio. Além do grupo que não se manifestou sobre esta formação (23\%), ainda encontramos um sujeito (7\%) que a considerou parcial, na medida em que os formadores enfatizam os aspectos teóricos dos conteúdos, deixando de lado a questão de sua aplicação prática.

Percebemos nas falas de todos esses sujeitos, tanto nas que defendem quanto nas que negam a consistência da formação oferecida, uma sensação de incompletude dos cursos de Biblioteconomia (não podem abarcar tudo), expressa como algo inerente a esse nível de ensino, o que os levou a se colocarem a favor de processos de formação continuada. A maioria desses profissionais experientes (65\%) tem se valido de cursos de atualização (desde os mais rápidos até a pósgraduação stricto-sensu - mestrado) para obter conhecimentos que lhes permitam atuar em BD. Isto ocorre por que a maioria realizou sua graduação há muitos anos atrás. Outras formas de atualização para o trabalho em BD, utilizadas por esses profissionais, foram: participações em eventos; e estudo / leitura de textos específicos, troca de experiências entre colegas de trabalho. Podemos, então, concluir que os bibliotecários experientes tanto apresentam críticas à formação recebida como à oferecida na atualidade.

Para os recém formados, os cursos realizados também possuem lacunas. Os que se vinculavam à universidade localizada no estado do Rio de Janeiro indicaram que não havia uma disciplina voltada especificamente para o tema BD; já o respondente que realizou seu curso em Minas Gerais disse que, apesar de ter tido essa disciplina em seu currículo, teve problemas de ordem didática. De qualquer forma, a maior parte desses respondentes considerou as disciplinas insuficientes em termos de preparar o MIP, uma vez que não têm a BD como foco específico; elas abordam a questão de forma transversal, o que torna o conteúdo superficial, incompleto e fragmentado. Ficou também registrada a ênfase em conteúdos teóricos em detrimento de experiências práticas, ou seja, a falta de situações concretas para aplicação da teoria. 
Quanto à realização do estágio supervisionado, componente curricular indispensável na formação de um profissional, verificamos que nenhum respondente teve essa atividade orientada para BD. Tal constatação nos permite inferir uma despreocupação com a formação do MIP e à expansão da realidade virtual na sociedade em geral e, em particular, na área da biblioteconomia. Os registros desses sujeitos ainda sugerem a existência de sutis mecanismos de exclusão dos alunos das propostas de estágio feitas por instituições que possuem esse tipo de serviço. Além desses problemas, os recém formados destacaram a falta de oportunidades de estágio, especialmente em BD.

Inferimos, então, que os cursos desses respondentes ainda privilegiam a formação do bibliotecário tradicional, oferecendo uma visão superficial da problemática BD; consequentemente prejudicam a formação do MIP.

A segunda questão desta pesquisa se dirigiu às dificuldades desse profissional em seu trabalho. Aqui consideramos apenas as respostas dos profissionais experientes, o que nos levou a perceber três ordens de problemas, a saber:

(a) nascimento da BD no bojo de uma biblioteca tradicional - ainda que essa origem seja a mais comum, ela produz efeitos diversos, entre os quais se destaca a transposição da lógica da administração da biblioteca tradicional para a BD. A migração lenta de um modelo para outro dificulta a expressão das potencialidades da BD. Daí ter sido enfatizada a necessidade da BD nascer de um projeto próprio, com softwares específicos de gestão que dêem conta da adequada utilização das tecnologias digitais de ponta no tratamento das informações. Ficou clara, também, a interferência negativa de profissionais muito especializados na gestão da biblioteca tradicional que, ao se inserirem em $B D$, comprometem a viabilização de propostas que têm outra natureza, por serem essencialmente virtuais. Nesses contextos, as resistências acabam aparecendo e prejudicando as inovações;

(b) o processo de gestão da biblioteca - os problemas levantados referem-se: à falta de apoio do setor de informática; quantitativo insuficiente de pessoal de apoio (poucos funcionários para a quantidade de tarefas); desatualização das bases de dados, o que acaba por emperrar as ações dos bibliotecários; recursos tecnológicos obsoletos; sobrecarga de trabalho para o bibliotecário; falta de apoio das agências de fomento; usuários muito exigentes, que não compreendem as dificuldades da biblioteca e de seus profissionais;

(c) o corpo de conhecimentos do próprio bibliotecário - que, na maioria das vezes, não dá conta de todas as possibilidades que uma BD pode oferecer. Esse conhecimento, fruto de uma formação realizada há vários anos e questionável, passa a exigir desse profissional esforço 
contínuo de estudo / aperfeiçoamento. No entanto, não são todos que se lançam em cursos ou eventos de reciclagem; muitos se limitam a ler (leituras escolhidas por conta própria ou por sugestão de algum colega) ou a trocar experiências em conversas informais com companheiros de trabalho. Tais opções redundam em saber fragmentado, desconectado de um projeto específico de BD.

Cabe destacar que encontramos um grupo significativo de profissionais experientes ( $4-23 \%$ ), afirmando que não sentiam qualquer dificuldade em relação ao seu trabalho; buscamos, então, verificar os motivos dessa segurança. Três deles disseram que constantemente participavam de cursos e eventos na área, mas um deles registrou que a prática cotidiana lhe dava os ensinamentos necessários para enfrentar os desafios da BD. Tais posições nos levam a inferir a existência de processos pouco comprometidos com o saber-fazer. Não há prática que não tenha dificuldades, que não enfrente desafios; basta apenas refletir criticamente sobre ela.

Para complementar nossas inferências a respeito das dificuldades de trabalho do bibliotecário, julgamos interessante considerar o que os recém formados disseram em termos de realização de estágios. Os problemas que passaram como alunos acabam se refletindo na prática profissional. Como destacamos anteriormente, eles não conseguiram estagiar em BD; também não tiveram atividades extracurriculares que os levassem a conhecer melhor esse tipo de biblioteca. Afirmaram, ainda, que não tinham tempo para outras atividades, fora do horário das aulas, pois trabalhavam. É provável que essas limitações contribuam para uma visão simplificada do que seja uma BD e acabem levando o profissional a não ver dificuldades no seu trabalho ou a ver as dificuldades fora de si, ou seja, as dificuldades passam a se situar nas tecnologias, na falta de apoio financeiro ou de pessoal, no usuário.

A última questão de nosso estudo procurou saber que caminhos esses profissionais utilizam para manter sua formação atualizada.

A participação em cursos (treinamentos, capacitações, especializações) constitui a estratégia principal utilizada por esses profissionais, sendo estimulada por suas instituições com vistas ao aprofundamento dos conhecimentos na área de BD. Um grupo significativo dos profissionais com experiência (70\%) afirmou lançar mão desse instrumento. No entanto, nas falas desses sujeitos, surgiu um destaque a cursos gratuitos, no sentido de que eram valorizados por que o investimento se tornava menor. Um pergunta, então, pode ser apresentada sobre a relevância desses cursos. Sabemos que muitos deles são de curta duração, tendendo a acrescentar pouco aos conhecimentos dos participantes. Esse fato sinaliza limitações nos processos de formação continuada. A participação em eventos da área também aparece como outra estratégia utilizada. Cabe registrar uma prática que começa a 
aparecer: a criação de comunidades virtuais onde os profissionais trocam informações sobre suas experiências.

As respostas oferecidas ainda nos permitiram perceber que 0 apoio dado pelas instituições aos profissionais para se especializarem refere-se, basicamente, à liberação de carga horária; o compromisso com os custos é bem mais difícil. Somente nas respostas de dois respondentes $(12 \%)$, observamos indícios de que suas instituições buscavam realizar uma política de incentivo à formação continuada. Na maioria das falas ficou evidente que cabe aos bibliotecários a responsabilidade de escolher os cursos, treinamentos e eventos e, na maioria das vezes, arcar com as despesas.

As dificuldades em relação ao aperfeiçoamento profissional não estão apenas no nível da profissão; os recém formados também revelaram um desconhecimento das possibilidades que sua própria universidade oferecia em termos de formação continuada. A maior parte deles nem sabia que sua instituição tinha mestrado nessa área. Os professores foram destacados como os estimuladores de estudos continuados.

Ainda que nossas questões de estudo não estivessem interessadas em identificar as atividades desenvolvidas por um MIP, não podemos deixar de registrar aqui a visão desses sujeitos sobre elas. As perguntas dos questionários que buscavam saber: (a) se eles sabiam quais eram os serviços que caracterizavam uma biblioteca digital; (b) quais eram as atividades específicas de uma biblioteca tradicional que permanecem na $\mathrm{BD}$; e (c) quais as atividades básicas que o Moderno Profissional da Informação realiza em uma $\mathrm{BD}$, receberam respostas que oferecem uma série de pistas que podem ser aprofundadas. Delas pode-se extrair, por exemplo, um rol de atividades práticas conduzidas por bibliotecários em $B D$, para ser analisado nos cursos de formação à luz da teoria e das possibilidades dos recursos digitais. Foi importante apresentar essas perguntas aos profissionais para que pudéssemos ter uma ideia de sua experiência com BD e, assim, compreender melhor as respostas dadas às perguntas do questionário que estavam diretamente relacionadas às questões de pesquisa.

\section{Considerações finais}

A conclusão desta pesquisa se dá no confronto entre nossa abordagem teórica e os achados anteriormente apresentados.

$\mathrm{Na}$ literatura, verificamos que o MIP se destaca como um especialista na busca seletiva da informação, sendo capaz de enfrentar o desafio da avassaladora disseminação de dados, o que vai exigir, de pronto, o domínio das tecnologias de informação e comunicação (TARAPANOFF, 1999). Amaral (1998) vê esse profissional como um 
agente de mudança, o que vai demandar a capacidade de gerenciar recursos informacionais. Já Pando e Guimarães (2006) destacam a capacidade de mediar informações em contextos marcados pela aceleração. Portanto, a visão que emerge entre os autores estudados é a de um gestor da informação: alguém que saiba desenvolver planejamento e administração estratégicos, o que vai muito além do domínio de métodos e técnicas de processamento da informação.

Com a pesquisa de campo depreendemos que a formação desse profissional está muito longe de privilegiar o perfil do MIP, especialmente por não possibilitar o amplo domínio das tecnologias digitais, que hoje dão suporte à gestão da informação em rede, e pela dificuldade de levar os alunos a praticarem aquilo que aprenderam (conteúdos tratados de forma limitada, fragmentada e transversal) na teoria. Os estágios são limitados e realizados em bibliotecas tradicionais. Nenhum dos sujeitos recém formados conseguiu realizar estágio em BD. Sem um estágio (nem que fosse de observação) em $\mathrm{BD}$, os alunos não podem perceber a complexidade da gestão da informação. Assim, a tendência será, caso venham a ter que se inserir em uma biblioteca onde o paradigma é totalmente diferente (tem como base a virtualidade dos dados), reproduzir as práticas tradicionais.

Cabe afirmar que a formação do bibliotecário ainda não atende à dimensão de MIP e, portanto, muitos estudos devem ser conduzidos para tornar essa proposta uma realidade.

Outra conclusão que aqui se impõe refere-se às dificuldades de atuação em BD. Vimos, na revisão da literatura, que é usual a criação da BD no bojo de uma biblioteca tradicional. Trata-se de um processo evolutivo que acaba levando as marcas de uma prática baseada em armazenamento / ordenação de papeis. Assim, nossos respondentes, bibliotecários experientes atuando em BD, registraram suas dificuldades (típicas de processos tradicionais de gestão da informação), sem enfatizar o princípio básico da BD - a preocupação deixa de ser com o lugar onde se encontram os documentos para concentrar-se no acesso. O lugar passa a ser secundário tanto para o bibliotecário como para o usuário. A biblioteca aponta as fontes de informação sem, necessariamente, possuir a propriedade física das mesmas (LEVACOV, 2000). Então, o bibliotecário, na condição de MPI, precisa ser capaz de depurar as informações, garantindo sua confiabilidade. É nesse aspecto crucial que ele vai fazer a diferença. Um usuário, com alguma experiência em navegação na internet, é capaz de localizar a informação e acessá-la, mas conhecer a sua procedência é algo muito complexo.

As respostas encontradas nos permitem concluir que os sujeitos dessa pesquisa encontram-se preocupados com os processos de organização de suas bases de dados, que passam a ser online. Há, portanto, indícios de que ainda se prendem à função básica da biblioteca 
tradicional, que é manter a memória coletiva da sociedade. Com a internet, a memória assume outras dimensões: ela se torna volátil, estando em constante transformação. Isto vai levar a Ciência da Informação e seus profissionais a repensarem questões como autoria, autenticidade e permanência (LEVACOV, 2000). Torna-se, pois, urgente que a formação desse profissional se volte para o novo mundo que se abre com as BD. Nenhum dos respondentes abordou essas questões em suas respostas. Isto evidencia que o caminho dessas instituições, entre nós, ainda está começando.

Por último, estabelecemos as conclusões sobre a formação continuada desses profissionais. Vimos na literatura que, de um modo geral, o profissional da informação é apontado como o principal responsável por sua educação continuada, tendo em vista que é quem melhor conhece suas necessidades (NOCETTI,1982). No entanto, esse mesmo autor aponta vários problemas que levam esse profissional a encontrar dificuldades no seu aperfeiçoamento, entre eles: questões financeiras; pouca oferta de cursos nessa área; inexistência de relação entre as atividades de formação continuada e a melhoria na carreira profissional; sobrecarga de trabalho, o que impede saídas para os processos de aperfeiçoamento; e escassez de literatura sobre pesquisas nessa área.

As respostas encontradas na pesquisa de campo não diferem muito do que selecionamos na revisão da literatura. Acreditamos que, nesse ponto, está a maior vulnerabilidade da formação do bibliotecário na perspectiva de MIP. Uma vez que os cursos de graduação não privilegiam o perfil de MIP, era de se esperar que os bibliotecários tivessem melhores oportunidades para os processos de aperfeiçoamento; mas não é isso que observamos com a pesquisa.

Essa conclusão sugere, pois, a necessidade de novos estudos que aprofundem sugestões dos bibliotecários para sua formação continuada.

Sem dúvida, estamos em outra etapa do processo evolutivo das bibliotecas e o bibliotecário precisa se preparar para assumir sua identidade de 'cibertecário'. Nesse sentido, ele é um desbravador, um pioneiro e o que produzir será a base de uma nova visão de biblioteca e informação.

\section{Referências}

AMARAL, S. A. Marketing: abordagem em unidades de informação. Brasília: Thesaurus, 1998.

ARRudA, M. D. A. C. C.; MARTEleto, R. M.; SOUZA, D. B. Educação, trabalho e o delineamento de novos perfis profissionais: o bibliotecário em questão. Ciência da Informação. Brasília, v. 29, n. 3, p.14-27, set./dez. 2000 . 
http://revista.ibict.br/index.php/ciinf/article/view/213/188> Acesso em jan. 2010

BARDIN, L. Análise de conteúdo. Lisboa: Edições 70, 2000.

CASTRO, C. A. Formação do profissional da informação: abordagem crítico reflexiva. In: (Org.). Ciência da informação e biblioteconomia: múltiplos discursos. São Luis: EDUFMA; EDFAMA, 2002, p.185-199.

CUNHA, M.B. Das bibliotecas convencionais às digitais: diferenças e convergências. Perspectivas em Ciência da Informação, v.13, n.1, p.2-17, jan/abr.2008. Disponível em:

http://portaldeperiodicos.eci.ufmg.br/index.php/pci/article/viewFile/221/3 88> Acesso em fev.2010.

GUIMARÃES, J.A.C. A ética na formação do bibliotecário. Palavra-chave, São Paulo, v.8, p:5-8, out. 1994.

GUIMARÃES, J. A. C.; GUAREZZI, S. Divulgação profissional: uma proposta pedagógica como suporte ao desenvolvimento da profissão bibliotecária no Brasil. Transinformação, Campinas, v. 6, n.1/3, p. 43-59, jan./dez. 1994.

LEVACOV, M. Bibliotecas virtuais. Revista da FAMECOS: Mídia, Cultura e Tecnologia. Porto Alegre, n. 6, p. 70-85, 1997. Disponível em: $<$ http://www.ultra.pucrs.br/famecos/rf6.maril.html>. Acesso em: maio 2007.

Bibliotecas virtuais. In: MARTINS, F. M.; SILVA, J. M. (Org) Para navegar no século XXI: tecnologias do imaginário e cibercultura. Porto Alegre, RS: Edipucrs, 2000. p. 261-286.

LÉVY, P. As tecnologias da inteligência e o futuro do pensamento na era da informática. 13. ed. São Paulo: Ed. 34, 2004.

MARCONDES, C. H. Bibliotecas digitais: saberes e práticas. Salvador; Brasília: EDUFBA; IBICT, 2006.

MORIN, E. Introdução ao pensamento complexo. Lisboa: Instituto Piaget, 2000.

MUELLER, S. P. M. O ensino de Biblioteconomia no Brasil. Ciência da Informação, Brasília, v. 14, n. 1, p. 3-16, jan./jun. 1985.

NOCETTI, M. A. Educação continuada para bibliotecários: revisão de literatura. In: MACHADO, U. D. (Org). Estudos avançados em biblioteconomia e ciência da informação. Brasília: ABDF, 1982. p 14-37.

PANDO, D. A; GUIMARÃES, J. A. C. O Profissional da informação e as atividades de organização da informação /conhecimento. Interatividade. 
Andradina (SP), v. 1, n. 2, 2006. Disponível em: <http://www.firb.br/interatividade/edicao2/_private2/pando.htm > . Acesso em: jun. 2010.

PONJUAN, D. G. Does the modern information professional have a life cycle? FID News Bulletin, v. 43, n. 3, p. 61, mar. 1993.

REZENDE, A. P. Centro de informações jurídico-eletrônico e virtual. Ciência da Informação, v. 29, n. 1, p. 51-60, jan./abr. 2000. Disponível em: <http://www.ibict.br/cionline/artigos/>. Acesso em: ago. 2008.

RODRIGUES, E. Bibliotecas virtuais e cibertecários: o futuro já começou. Cadernos de $B A D$, v. 3, p. 23-24, 1995.

SCHAFF, A. A sociedade informática: as conseqüências sociais na segunda revolução industrial. 3 ed. São Paulo: UNESP, 1992.

SMITH, J.W. O que é documentação. São Paulo: Brasiliense, 1986.

STRAUSS, A.; CORBIN, J. Pesquisa qualitativa: técnicas e procedimentos para o desenvolvimento de teoria fundamentada. Porto Alegre: Artmed, 2008.

TARAPANOFF, K. Perfil do profissional da informação no Brasil: diagnóstico de necessidades de treinamento e educação continuada. Brasília, DF: IEL/DF, 1999.

TARAPANOFF, K; ARAÚJO JÚNIOR, R. H. de; CORMIER, P. M. J. Sociedade da informação e inteligência em unidades de informação. Ciência da informação, Brasília, v. 29, n. 3, p. 91-100, set./ dez. 2000. Disponível em: <http://revista.ibict.br/ciinf/index.php/ciinf/article/view/231/206 > Acesso em: out. 2008. 